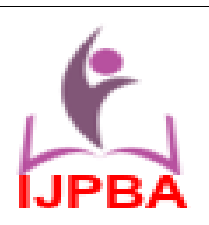

Contents lists available at www.ijpba.in

International Journal of Pharmaceutical and Biological Science Archive

NLM (National Library of Medicine ID: 101738825$)$

Index Copernicus Value 2019: 71.05

Volume 9 Issue 2; March-April; 2021; Page No. 07-13

\title{
EVALUATION OF ANTI ULCER ACTIVITY OF HYDROALCOHOLIC LEAVES EXTRACT OF LEUCAS ASPERA
}

\author{
Mr. Surjeet Kumar,* Mr. Narendra Patel, Dr. Prabhakar Budholiya \\ College of Pharmacy, Sri Satya Sai University of Technology and Medical Sciences, Sehore (M. P.) \\ Conflicts of Interest: Nil
}

Corresponding author: Mr. Surjeet Kumar

DOI: https://doi.org/10.32553/ijpba.v9i2.183

\begin{abstract}
The main aim of the study was to determine the phytoconstituents present in Leaves of Leucas aspera. The present study was therefore carried out to evaluate the anti-ulcer activity of Hydroalcoholic (70\% methanol) leaf extract of Leucas aspera in rats. The effect of Leucas aspera extract on gastric ulcer in rats in indomethacin induced gastric ulcers model and ethanol-induced models was studied using single dosing $(100,200 \mathrm{mg} / \mathrm{kg})$ and repeated dosing $(200 \mathrm{mg} / \mathrm{kg}$ for 5 days) approaches. Ranitidine $(50 \mathrm{mg} / \mathrm{kg})$ and cimetidine $(100 \mathrm{mg} / \mathrm{kg})$ were used as the standard drugs. Depending on the model, outcome measures were volume ulcer index. Data were analyzed using one-way analysis of variance and $P<0.05$ was considered as statistically significant. Leucas aspera significantly $(P<0.001)$ reduced gastric ulcer, respectively, in indomethacin induced gastric ulcers model and ethanol-induced models at the $200 \mathrm{mg} / \mathrm{kg}$ dose, which is comparable to the standard drugs. 5 days pre-treatment with Leucas aspera $200 \mathrm{mg} / \mathrm{kg}$ exhibited significant $(P<0.001)$ ulcer inhibition. Leucas aspera possesses both dose-dependent and time-dependent anti-ulcer effect in the two models. The oral median lethal dose $\left(\mathrm{LD}_{50}\right)$ is estimated to be higher than $2000 \mathrm{mg} / \mathrm{kg}$ for the crude hydroalcoholic extract, and secondary metabolites such as flavonoids, tannins, and saponins were present. The findings of this study confirmed that Leucas aspera has anti-ulcer pharmacologic activity due to one or more of the secondary metabolites present in it. Therefore, this study validates its anti-ulcer use in Ethiopian folk medicine. Further investigations on isolation of specific phytochemicals and elucidating mechanisms of action are needed.
\end{abstract}

Keywords: indomethacin.

\section{Introduction}

\section{Stomach Ulcer}

Stomach ulcers, which are also known as gastric ulcers, are painful sores in the stomach lining. Stomach ulcers are a type of peptic ulcer disease. Peptic ulcers are any ulcers that affect both the stomach and small intestines. Stomach ulcers occur when the thick layer of mucus that protects your stomach from digestive juices is reduced. This allows the digestive acids to eat away at the tissues that line the stomach, causing an ulcer.

Stomach ulcers may be easily cured, but they can become severe without proper treatment.

\section{Causes stomach ulcers}

Stomach ulcers are almost always caused by one of the following:

- an infection with the bacterium Helicobacter pylori (H. pylori)

- long-term use of nonsteroidal antiinflammatory drugs (NSAIDs), such as aspirin, ibuprofen, or naproxen

Rarely, a condition known as Zollinger-Ellison syndrome can cause stomach and intestinal ulcers by increasing the body's production of acid. This syndrome is suspected to cause less than 1 percent of all peptic ulcers. 


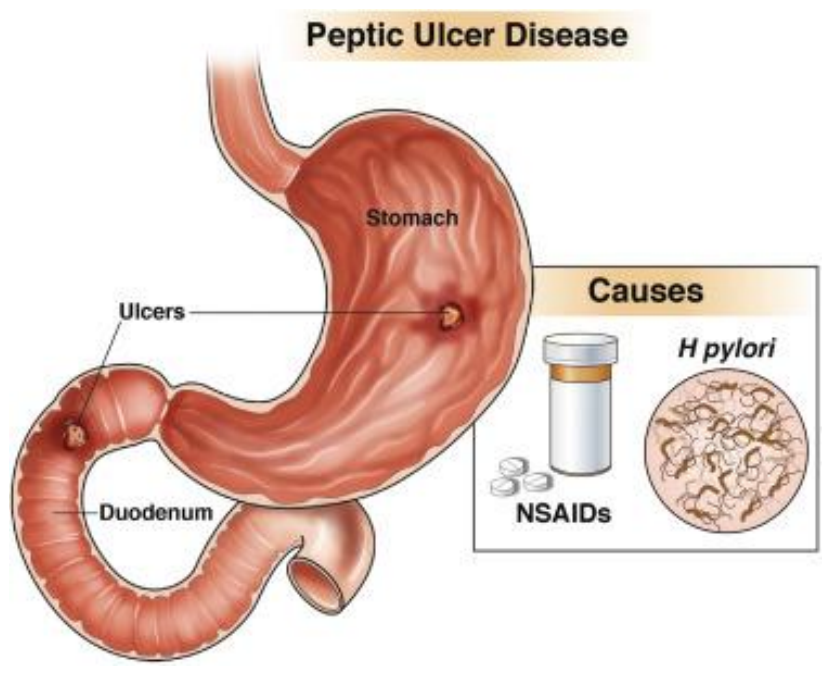

Figure 1: Peptic Ulcer

Symptoms of stomach ulcers

A number of symptoms are associated with stomach ulcers. The severity of the symptoms depends on the severity of the ulcer.

The most common symptom is a burning sensation or pain in the middle of your abdomen between your chest and belly button. Typically, the pain will be more intense when your stomach is empty, and it can last for a few minutes to several hours.

\section{Other common signs and symptoms of ulcers include:}

- dull pain in the stomach

- weight loss

- not wanting to eat because of pain

- nausea or vomiting

- bloating

- feeling easily full

- burping or acid reflux

- heartburn, which is a burning sensation in the chest)

- pain that may improve when you eat, drink, or take antacids

- anemia, whose symptoms can include tiredness, shortness of breath, or paler skin

- dark, tarry stools

- vomit that's bloody or looks like coffee grounds
Talk to your doctor if you have any symptoms of a stomach ulcer. Even though discomfort may be mild, ulcers can worsen if they aren't treated. Bleeding ulcers can become lifethreatening.

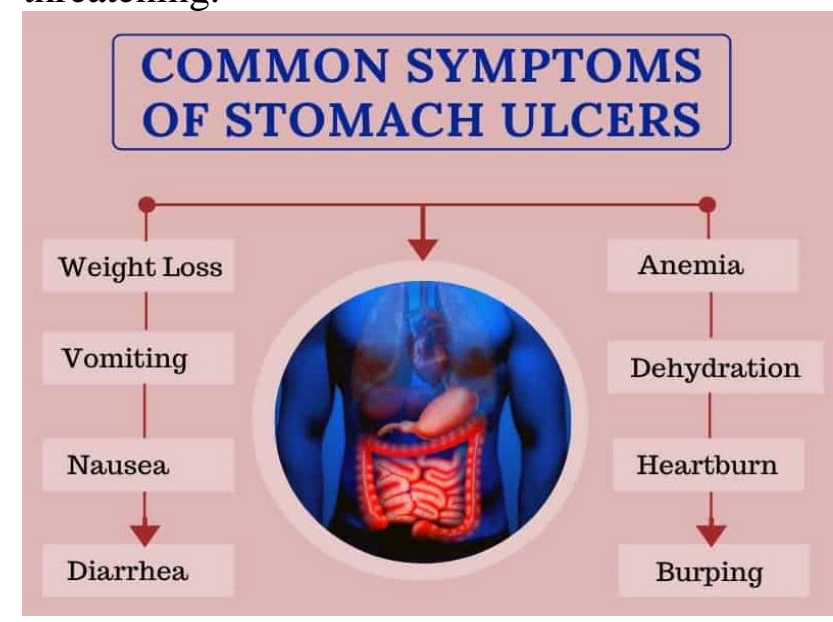

Figure 2: Symptoms of stomach ulcers

\section{Materials and methods:-}

\subsection{Collection of plant material}

The plant material was collected from local area of Bhopal. Drying of fresh Leaves was carried out in sun but under the shade. Dried Leaves were preserved in plastic bags and closed tightly and powdered as per the requirements.

\subsection{Extraction by maceration process}

65.5 gram leaves of Leucas Aspera were exhaustively extracted with hydroalcoholic extract solvent (Methanol 70\%) and using drug - solvent ratios (1:2) using maceration process (10hrs). The extracts were evaporated above their boiling points. Finally the percentage yields were calculated of the dried extracts (Mukherjee, 2007; Kokate, 1994).

\subsection{Determination of percentage yield}

The percentage yields of each extract were calculated by using following formula:

$$
\text { Percentage yield = } \frac{\text { Weight of Extract }}{\text { Weight of powder drug Taken }}
$$

\subsection{Qualitative evaluation}

The chemical tests were performed for testing different chemical groups present in extracts (Khandelwal, 2005; Kokate, 1994). The Leucas 
aspera leaves extract acquire was subjected to the precursory phytochemical analysis following standard methods by Khandelwal and Kokate. The extract was screened to identify the presence of various active principles of Alkaloids, glycosides, Diterpenes, saponins, flavonoids and phenol.

\subsection{Total Phenolic content estimation}

Procedure: The total phenolic content of the extract was determined by the modified FolinCiocalteu method. $10 \mathrm{mg}$ Gallic acid was dissolved in $10 \mathrm{ml}$ methanol, various aliquots of $5-25 \mu \mathrm{g} / \mathrm{ml}$ was prepared in methanol. $10 \mathrm{mg}$ of dried extract of plant material was extracted with $10 \mathrm{ml}$ methanol and filter. $2 \mathrm{ml}(1 \mathrm{mg} / \mathrm{ml})$ of this extract was for the estimation of Phenol. $2 \mathrm{ml}$ of each extract or standard was mixed with $1 \mathrm{ml}$ of Folin-Ciocalteu reagent (previously diluted with distilled water $1: 10 \mathrm{v} / \mathrm{v}$ ) and $1 \mathrm{ml}$ $(7.5 \mathrm{~g} / \mathrm{l})$ of sodium carbonate. The mixture was vortexed for $15 \mathrm{~s}$ and allowed to stand for $15 \mathrm{~min}$ at $40^{\circ} \mathrm{C}$ for colour development. The absorbance was measured at $765 \mathrm{~nm}$ using a spectrophotometer.

\subsection{Total flavonoids content estimation}

Procedure: Determination of total flavonoids content was based on aluminium chloride method (Olufunmiso et al., 2011). $10 \mathrm{mg}$ quercetin was dissolved in $10 \mathrm{ml}$ methanol, and various aliquots of $5-25 \mu \mathrm{g} / \mathrm{ml}$ were prepared in methanol. $10 \mathrm{mg}$ of dried extract of plant material was extracted with $10 \mathrm{ml}$ methanol and filter. $3 \mathrm{ml}(1 \mathrm{mg} / \mathrm{ml})$ of this extract was for the estimation of flavonoid. $1 \mathrm{ml}$ of $2 \% \mathrm{AlCl}_{3}$ methanolic solution was added to $3 \mathrm{ml}$ of extract or standard and allowed to stand for 15 min at room temperature; absorbance was measured at $420 \mathrm{~nm}$.

\subsection{In Vivo antiulcer activity}

Preliminary experiments were carried out on rats $(n=6)$. A Hydroalcoholic leaves extract of Leucas Aspera were administered orally in different doses to find out the range of doses which cause zero and $100 \%$ mortality of animals. Acute oral toxicity was conducted according to the method of Organisation for Economic Co-operation and Development (OECD) (OECD, 2001). Animals were kept fasting providing only water, amoxicillin microspheres were given p.o. in doses of 500, 1000 and $2000 \mathrm{mg} / \mathrm{kg} / \mathrm{p} .0$. administered orally for 4 days of six groups of rats $(n=6)$ and the animals were kept under observation for mortality as well as any behavioral changes for evaluation of a possible anti-ulcer effect.

\section{Experimental designs}

\section{Indomethacin induced gastric ulcer}

Group -1: Control

Group -2: Cimetidine (Standard)

Group -3: Hydroalcoholic leave extract of Leucas Aspera (100mg/kg, p.o.)

Group -4: Hydroalcoholic leave extract of Leucas Aspera (200mg/kg, p.o.)

\section{Ethanol induced gastric ulcers model}

Group -1: Control

Group -2: Cimetidine (Standard)

Group -3: Hydroalcoholic leave extract of Leucas Aspera (100mg/kg, p.o.)

Group -4: Hydroalcoholic leave extract of Leucas Aspera (200mg/kg, p.o.)

The animals were fasted for $24 \mathrm{~h}$ prior to the experiment. Under anaesthesia, ulcers were induced by applying indomethacin $(5 \mathrm{mg} / \mathrm{kg}$. p.o.) over the anterior serosal surface of the stomach for 60 seconds. The animals were treated with Cimetidine (100 mg/kg, p.o.), low dose of Hydroalcoholic leave extract Leucas Aspera $(100 \mathrm{~m} / \mathrm{kg}$ p.o.) or high dose of Hydroalcoholic leave extract of Leucas Aspera $(200 \mathrm{~m} / \mathrm{kg}$ p.o.) [once daily, for 5 days after the induction of ulcer, while the control group received only the vehicle. The rats were sacrificed on the $5^{\text {th }}$ day, the stomachs removed and cut open along the greater curvature (Khare et al., 2008). The ulcer index was determined using the formula:

Ulcer index $=10 / \mathrm{X}$

Where $\mathrm{X}=$ Total mucosal area/Total ulcerated area.

Based on their intensity, the ulcers were given scores as follows: 
$0=$ no ulcer, $1=$ superficial mucosal erosion, 2

$=$ deep ulcer or transmural necrosis,

$3=$ perforated or penetrated ulcer.

\section{Results and Discussion}

\subsection{Physical characteristics of extract}

Finally extraction of defatted flowers was done with Hydro alcoholic and \% yield was found to be $3.15 \% \mathrm{w} / \mathrm{w}$ and their characteristics are reported in table- 3.1 .

Table 3.1: Physical characteristics of extract

\begin{tabular}{|l|l|l|l|c|}
\hline Extracts & Consistency & Colour & Odour & \% Yield \\
\hline Hydro alcoholic & Solid & Dark Brown & Pungent & 2.68 \\
\hline
\end{tabular}

\subsection{Qualitative chemical test}

Results obtained from qualitative chemical tests are tabulated in Table-3.2.

Table 3.2: Quantitative chemical tests of extract of Leucas aspera

\begin{tabular}{|l|l|l|}
\hline S. No. & Test & Hydro alcoholic extract \\
\hline $\mathbf{1}$ & Alkaloids & $+\mathrm{ve}$ \\
\hline $\mathbf{2}$ & Carbohydrates & $+\mathrm{ve}$ \\
\hline $\mathbf{3}$ & Glycosides & $+\mathrm{ve}$ \\
\hline $\mathbf{4}$ & Saponins & $+\mathrm{ve}$ \\
\hline $\mathbf{5}$ & Phenols & $+\mathrm{ve}$ \\
\hline $\mathbf{6}$ & Flavonoids & $+\mathrm{ve}$ \\
\hline $\mathbf{7}$ & Proteins & $-\mathrm{ve}$ \\
\hline $\mathbf{8}$ & Diterpenes & $+\mathrm{ve}$ \\
\hline
\end{tabular}

+ ve - Present, - ve - Absent

3.3 Result of Total phenolic and total flavonoids content estimation (TPC)

Table 3.3: Estimation of total phenolics and total flavonoids content

\begin{tabular}{|l|l|l|l|}
\hline S. No & Extract & Total phenolic content $\mathbf{( m g} / \mathbf{m l})$ & Total flavonoids Content $(\mathbf{m g} / \mathbf{m l})$ \\
\hline $\mathbf{1}$ & Hydroalcoholic & 4.27 & 2.05 \\
\hline
\end{tabular}

\subsection{Results of In Vivo antiulcer activity}

Anti-ulcerogenic effect of Hydroalcoholic leaves extract Leucas aspera against ulcerogenic agents in rats (Ulcer index) (INDOMETHACIN INDUCED GASTRIC ULCERS MODEL)

Table 1: Indomethacin Induced Gastric Ulcers Model

\begin{tabular}{|l|l|}
\hline Treatment and dose & Ulcer index \\
\hline Control & $3.50 \pm 5.0$ \\
\hline Cimetidine $(100 \mathrm{mg} / \mathrm{kg}$, p.o. $)$ & $1.50 \pm 5.0^{* * * *}$ \\
\hline Hydroalcoholic leaves extract Leucas aspera $(100 \mathrm{mg} / \mathrm{kg}$, p.o. $)$ & $3.05 \pm 5.0^{* * *}$ \\
\hline Hydroalcoholic leaves extract Leucas aspera $(200 \mathrm{mg} / \mathrm{kg}$, p.o. $)$ & $2.40 \pm 5.0^{* * * *}$ \\
\hline
\end{tabular}

Values are expressed as mean \pm S.E.M. $(n=6)$.

Percent inhibition calculated as compared to control group.*** $P<0.001$, ** $P<0.01, * P<0.05$ (One-way ANOVA followed by Tukey's post hoc test). 


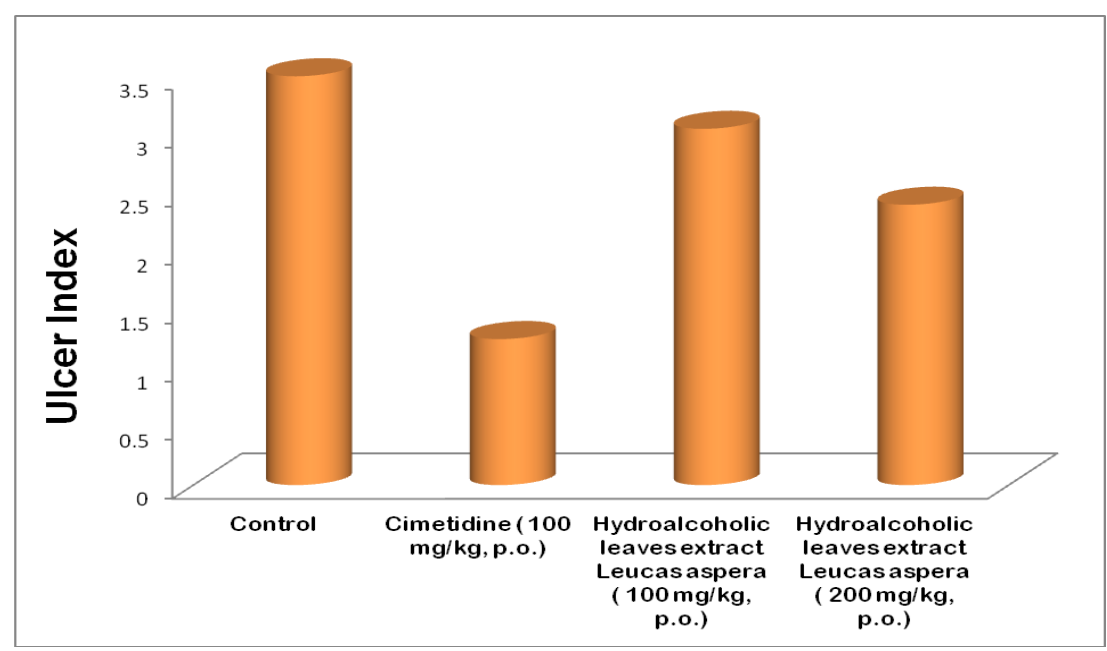

Figure 3: Anti-ulcerogenic effect of Hydroalcoholic leaves extract Leucas aspera against ulcerogenic agents in rats (Ulcer index)

Table 2: ETHANOL INDUCED GASTRIC ULCERS MODEL

\begin{tabular}{|l|l|}
\hline Group & Ulcer Index \\
\hline Vehicle & $5.733 \pm 0.16$ \\
\hline Ranitidine $(50 \mathrm{mg} / \mathrm{kg}$, p.o.) & $0.713 \pm 0.11$ \\
\hline Hydroalcoholic leaves extract Leucas aspera $(100 \mathrm{mg} / \mathrm{kg}$, p.o.) & $3.85 \pm 0.22$ \\
\hline Hydroalcoholic leaves extract Leucas aspera $(200 \mathrm{mg} / \mathrm{kg}$, p.o. $)$ & $2.911 \pm 0.11$ \\
\hline
\end{tabular}

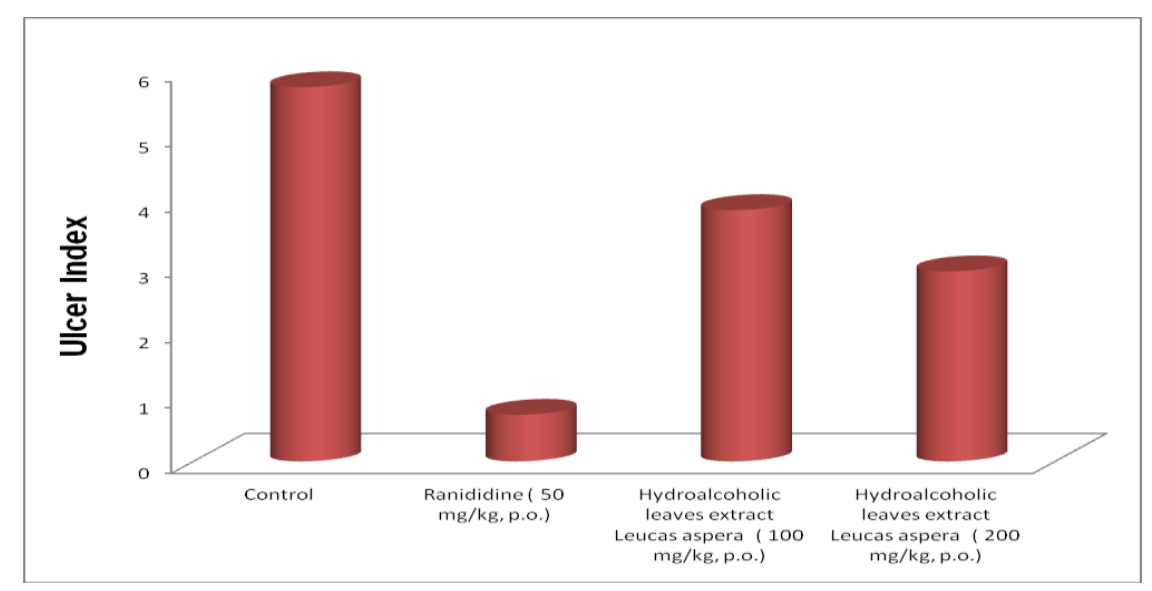

Figure 4: Anti-ulcerogenic effect of Hydroalcoholic leaves extract Leucas aspera against ulcerogenic agents in rats (Ulcer index) ethanol induced gastric ulcers model

The present study investigated the effect of Hydroalcoholic leaves extract Leucas aspera on the ulcers. Hydroalcoholic leaves extract Leucas aspera showed effect on the healing of gastric ulcers induced by indomethacin. It acts through the inhibition of cell wall biosynthesis that leads to the death of the bacteria. Hydroalcoholic leaves extract Leucas aspera was effective in reducing the ulcer area and the ulcer score. Leucas aspera has an antiulcer effect. It increased healing of indomethacin induced ulcer.

\section{Conclusion}

The analysis and characterization of bioactive compounds from plants is important to ascertain their medicinal value. The phytochemical analysis showed that the Leucas aspera plant extract contains a mixture of phytochemicals as Carbohydrates, Saponins, Glycosides, Diterpenes, Phenols and Flavonoids. The total phenolics and total flavonoids content for the hydroalcoholic extract was found to be 4.27and $2.05 \mathrm{mg} / \mathrm{ml}$ in flowers extract of Leucas aspera. The present study investigated the effect of 
hydroalcoholic leaves extract of Leucas aspera on the ulcers. Hydroalcoholic leaves extract of Leucas aspera showed effect on the healing of gastric ulcers induced by indomethacin. It acts through the inhibition of cell wall biosynthesis that leads to the death of the bacteria.hydroalcoholic leaves extract of Leucas aspera was effective in reducing the ulcer area and the ulcer score. Leucas aspera has an antiulcer effect. It increased healing of indomethacin induced ulcer.

\section{Reference}

1. Julia Fashner, MD, and Alfred C. Gitu, MD. Diagnosis and Treatment of Peptic Ulcer Disease and $H$. pylori Infection. American Family Physician. 2015;91(4):236-242. Accessed 6/24/ 2020.

2. American College of Gastroenterology. Peptic Ulcer Disease. Accessed 6/24/2020.

3. Perry S, Sanchez Md, Yang S, et al. Gastroenteritis and Transmission of _Helicobacter pylori_Infection in Households. Emerging Infectious Diseases. 2006;12(11):1701-1708. Accessed 6/24/2020.

4. National Institute of Diabetes and Digestive and Kidney Diseases. Definition \& Facts for Peptic Ulcers (Stomach Ulcers). Accessed 6/24/2020.

5. Shimamoto T, Yamamichi N, Kodashima S, et al. No Association of Coffee Consumption With Gastric Ulcer, Duodenal Ulcer, Reflux Esophagitis, and Non-Erosive Reflux Disease: A Cross-Sectional Study of 8,013 Healthy Subjects in Japan. 2013; 8(6):

6. Archived 2018-06-02 at the Wayback Machine, Prajapati MS, Patel JB, Modi K, Shah MB. Leucas aspera: A review. Phcog Rev [serial online] 2010 [cited 2012 Apr 28];4:85-7. Available from: http://www.phcogrev.com/text.asp?2010 /4/7/85/65330 .

7. R. Srinivasan (2011). "Leucas Aspera Medicinal Plant: A Review" (PDF). International Journal of Pharma and Bio Sciences. 2 (1): 153-159.
1. 8.Deb. D.B.(1983) "The Flora Of Tripura State" [vol. II]. Today \& Tomorrow's Printers and Publishers. pp.314-338. 24-B15, Deshbandhu Gupta Road,Karol Bagh, New Delh

8. Davidson-Hunt I.2000: Ecological ethno botany: stumbling toward new practices and paradigms. MASA J. , 16:1-13,2000

9. UNESCO. Culture and Health, Orientation Texts - World Decade for Cultural

2. Development 1988 - 1997, Document CLT/DEC/PRO - 1996, Paris, France, pgs.129,1996.

10. UNESCO. FIT/504-RAF-48 Terminal Report: Promotion of Ethno botany and the Sustainable Use of Plant Resources in Africa, pgs. 60, Paris, 1998.

11. Bassam Abdul Rasool Hassan. Medicinal Plants (Importance and Uses). Clinical Pharmacy Discipline, School of Pharmaceutical Sciences, University of Sains Malaysia, 11800, Minden, Penang, Malaysia, Pharmaceutica Analytica Acta, 2012

12. Dixit,S Huma Ali. Antioxidant Potential Some Medicinal Plants of Central India,Journal of Cancer Therapy, 2010, 1, 87-90 Doi:10.4236/jct.2010.12014 Published Online June 2010 .

13. Nwankwo, J.O., 2011. Potential Anti cancer and Antiviral Agents from West African Phytochemicals. University of Nigeria Press. Pp 156162.

14. WHO.1991b. Traditional Medicine and Modern Health Care. WHO Geneva.

15. World Health Organization (WHO). National Policy on Traditional Medicine and Regulation of Herbal Medicines. Geneva: 2005. Report of WHO global survey.

16. Xutian S, Zhang J, Louise W. New exploration and understanding of traditional Chinese medicine. Am J Chin Med. 2009; 37:411-26.

17. Barnes P. M, Bloom B, Nahin R. Complementary and alternative medicine use among adults and children: United States, 2007. CDC National Health Statistics Report \# 12. 2008. 
18. Cohen P. A, Ernst E. Safety of herbal supplements: A guide for cardiologists. Cardiovasc Ther. 2010; 28:246-53.
19. Engebretson J. Culture and complementary therapies. Complement Ther Nurs Midwifery. 2002; 8:177-84. 